\title{
Monte Carlo and molecular dynamics studies for the colour rewritable films
}

\author{
H.Okajima ${ }^{1}$, T.Kawamura ${ }^{1}$, C.Kongo ${ }^{1}$, Y.Hiwatari ${ }^{1}$, \\ N.Urakami ${ }^{2}$, R.Hayashi ${ }^{3}$, K.Kato ${ }^{4}$ \\ 1 Department of Computational Science, Kanazawa University, \\ Kakuma-machi, Kanazawa 920-1192, Japan \\ 2 Department of Physics, Biology, and Informatics, Yamaguchi University, \\ Yamaguchi, 753-8512, Japan \\ 3 School of Information Science, \\ Japan Advanced Institute of Science and Technology, \\ 1-1 Asahidai, Tatsunokuchi, Nomi, Ishikawa 923-1292, Japan \\ 4 RICOH Company, Ltd. Chemical Products R\&D Ctr., \\ 16-1 Honda-machi, Numazu-city, Shizuoka, 410-0004, Japan
}

Received July 25, 2000, in final form September 6, 2000

The structure of the developers plays an important role in the colouring/decolouring process for the colour rewritable films. We study the chain-like polymers structure of the developer through both the Monte Carlo and molecular dynamics simulations. In these simulations we focus our attention on the thermal (temperature) effects as well as the effective interaction between developers (chain-like polymers), and with these how the lamellar structure can be constructed when the system is quenched from high temperature (low density) to low temperature (high density). We found the transition of the states from a disordered state to an aggregated state at a temperature $(282 \mathrm{~K})$. We obtained the lamellar structure in a preferable condition of the potential parameter, while in either smaller or larger interactions, it is rather difficult for the developer chains to form lamellar structures.

Key words: colour rewritable film, leuco dye, developer, lamellar structure, Monte Carlo simulation, molecular dynamics simulation

PACS: $05.70 . J k$

\section{Introduction}

With a recent advancement of technologies of computer (both soft and hard wares), the computer simulation comes to a new age that it can be notably helpful to design new materials in a much higher cost-performance than experimental ways which usually take long time to go to final objects. Examples are seen ev- 
erywhere, like a molecular design by which structures of condensed matter can be controlled from the origin of the molecular level with either the molecular dynamics simulation or Monte Carlo simulation. It is expected that the development of digital informatizing will contribute to paperless. However, the consumption of paper is still increasing. One reads articles easier in sheets of paper rather than in display. In view of the environmental problem, the development of rewritable thermal recording paper is absolutely necessary. The colour rewritable (CR) film is one of the thermal rewritable recording papers, which is composed of the leuco dyes and developers. The colouring/decolouring process of the CR film originates from the structure of the leuco dyes and the developers [1-3]. In the decolouring state, the developers are crystallized and not directly contacted with the leuco dyes. When the CR films are heated from the decolouring states, the crystallized developers are melted and coloured because the leuco dyes can contact with the developers and then induce changes of the electronic states. By slow cooling of this colouring state, the developers are crystallized and separated from leuco dyes and then the system turns to the decolouring state. By rapid quenching, however, the CR films are solidified in a colouring metastable state. For a system of pure developers without leuco dyes, the developers can take two different structures by slow cooling and raid quenching. These structures correspond to the colouring and decolouring structures of the CR films $[1,2]$. Thus different structures obtained by slow cooling and rapid quenching rely critically on the developers. In this paper, we investigate the structure of the developers by using both Monte Carlo and molecular dynamics simulations. In Monte Carlo simulation, the temperature dependence of the structure of developers is studied at low concentrations. In molecular dynamics simulation, the interaction between head molecules of each developer is varied to study the change of the structure of developers.

\section{Model and simulation method}

CR films are composed of leuco dyes and developers. For the colouring/decolouring process of the CR films, we have performed our simulations for a pure developer system as a first step. Typical developers have a long alkyl chain, as shown in figure 1a. The developer molecules are composed of two parts, i.e., the head monomer and the tail monomers in an alkyl chain. It is known that the colouring/decolouring process strongly depends on the kind of the head monomers [3]. We simplified the developer molecules as shown in figure 1.

\subsection{Monte Carlo simulation}

Each developer is composed of 20 monomers and each bond length is $1.53 \AA$. The bond angle is fixed at 109.5 degrees. The head monomer on each developer has an attractive interaction, while the other tail monomers have got repulsive interactions. 
(a)

\section{$\mathrm{CH}_{3}\left(\mathrm{CH}_{2}\right)_{2} \mathrm{R}$}

(b)

\section{arovorouso}

Figure 1. (a) The molecular structure of a developer. (b) The model of the developer chain. The large circle is the head monomer and the small circles are the other tail monomers.

We used the Lennard-Jones potential between the head monomers alone.

$$
E_{\text {attraction }}=4 \epsilon\left\{\left(\frac{\sigma}{r}\right)^{12}-\left(\frac{\sigma}{r}\right)^{6}\right\}
$$

where $\mathrm{r}$ denoted the distance between a pair of head monomers. In our simulations, $\epsilon=9 \epsilon_{0}$, where $\epsilon_{0}$ was $0.1984 \mathrm{Kcal} / \mathrm{mol}$, and $\sigma$ was $3.6239 \AA$. The repulsive interaction between tail monomers and between heads and tail monomers was assumed by

$$
E_{\text {repulsion }}= \begin{cases}4 \epsilon\left\{\left(\frac{\sigma}{r}\right)^{12}-\left(\frac{\sigma}{r}\right)^{6}+\frac{1}{4}\right\}, & r \leqslant 2^{\frac{1}{6}} \sigma, \\ 0, & r>2^{\frac{1}{6}} \sigma,\end{cases}
$$

where $\epsilon=\epsilon_{0}$.

The torsional potential in the intrachain monomers was defined as

$$
E_{\text {torsion }}=10 \epsilon_{0}\left(1-\cos \left(\theta-\theta_{0}\right)\right)^{2},
$$

where $\theta$ denoted the dihedral angle of a chain and $\theta_{0}$ was 180 degrees. For the intrachain interaction between $i$ th and $j$ th monomers, where $j>i+3$, we also used the potential energy given by equation (2). For the motion of the chains, both translations and rotations were involved. The rotations of the torsional angles were permitted only in each intrachain. Monte Carlo simulations were performed in three dimensional space.

\subsection{Molecular dynamics simulation}

Each developer is composed of 20 monomers. In molecular dynamics simulations, the Lennard-Jones potentials, given by equation (1) were used as interactions between all monomers. The interaction between head monomers is assumed to have a different value of $\epsilon$ from the interaction between other monomers. For the interaction between the head monomers, we studied three different cases, i.e., $\epsilon=3 \epsilon_{0}, 6 \epsilon_{0}$, 
and $9 \epsilon_{0}$. For the interaction between heads and tail monomers and between tail monomers, we all assumed $\epsilon=\epsilon_{0}$. The angle-bend potential energy was assumed to have the following form.

$$
E_{\text {bend }}=\frac{1}{2} k_{i j k}\left(\theta_{i j k}-\theta_{0}\right)^{2},
$$

where the subscript $i j k$ denotes subsequent $i$ th, $j$ th, and $k$ th monomers, $\theta_{i j k}$ was the bond angle between $i j$ bond and $j k$ bond, $\theta_{0}$ was 108 degrees, and $k_{i j k}$ was $500 \mathrm{Kcal} / \mathrm{mol} /$ degree $^{2}$. The bond length was fixed at $1.53 \AA$ by using the noninteractive matrix method $[4,5]$. We performed molecular dynamics simulations for two dimensions in the present work aiming at more effective calculation in a limited short time than for three dimensions as well as for its simplicity. To save the computational time, we used the cell index method [6]. The temperature was kept constant by the constraint method.
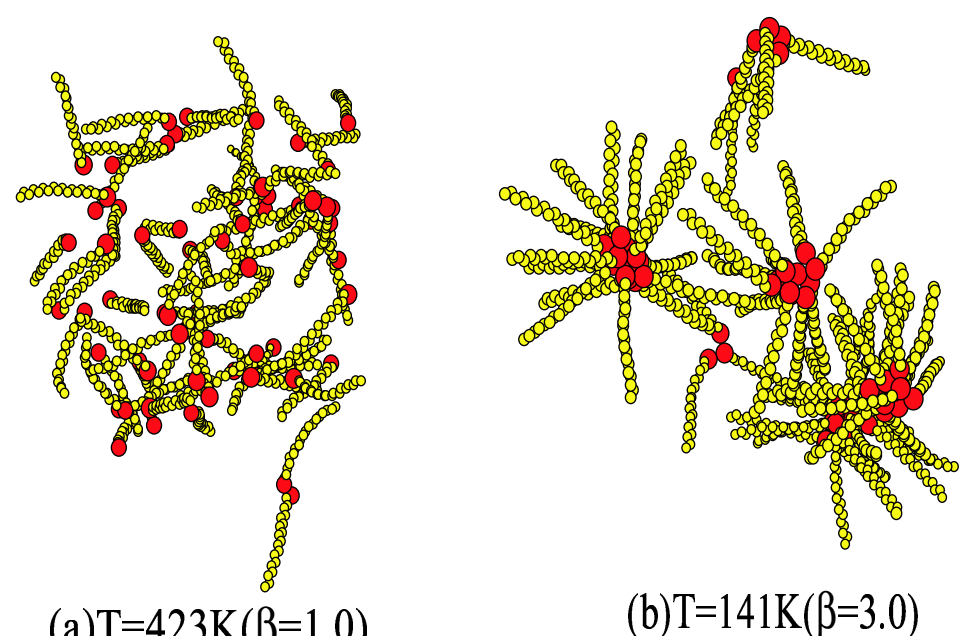

(a) $\mathrm{T}=423 \mathrm{~K}(\beta=1.0)$

(b) $\mathrm{T}=141 \mathrm{~K}(\beta=3.0)$

Figure 2. The typical configurations of the developers obtained by the Monte Carlo simulation. The temperatures are (a) $423 \mathrm{~K}$ and (b) $141 \mathrm{~K}$.

\section{Results}

\subsection{Monte Carlo simulation}

We performed Monte Carlo simulations to investigate the temperature dependence of the developer structures in three dimensions. In our simulations, the number of the chain was 63 and the simulation box length was $80 \AA$. The concentration of the developer chains was thus very low (number density $\rho=0.061$ ). The temperature was varied from $423 \mathrm{~K}$ to $141 \mathrm{~K}$.

Figure 2 shows a typical configuration of developers. At high temperature $T=$ $423 \mathrm{~K}$, the developer chains dispersed almost uniformly in the simulation box. At low 


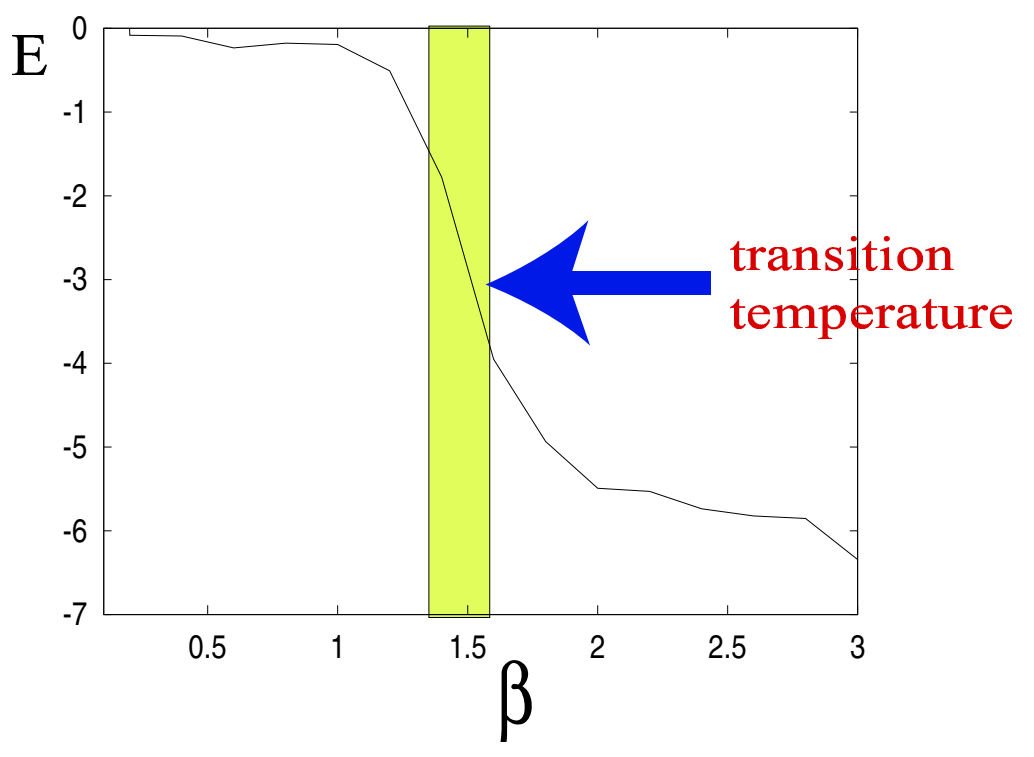

Figure 3. Average head energy of the developers obtained by the Monte Carlo Simulation.

temperature $T=141 \mathrm{~K}$, the developer chains aggregate and make some domains. The head monomers of the developers aggregate to the center of each domain because of the attractive energy between the head monomers. From the temperature dependence of the total energy, the developer configurations change rapidly from disordered states to the aggregated states around the temperature $282 \mathrm{~K}$ as shown in figure 3. In real CR films, the change from the colouring state to the decolouring state takes place in a similar way.

In order to see further correspondence between our result and experimental information for real CR films we have carried out another Monte Carlo simulation by compression of the system. Figure 4 shows a configuration obtained by such Monte Carlo calculation as the box size was reduced from $80 \AA$ to $40 \AA$, in which partially layered structures are found.

\subsection{Molecular dynamics simulation}

We performed two dimensional molecular dynamics simulations. The number of the developer chains was 120 and the simulation box size was $160 \AA$. In these simulations, we investigated the configurations of the developers for three different head potential interactions. We used the Lennard-Jones potential, equation (1), between monomers. The head potential interactions were taken as $\epsilon=3 \epsilon_{0}, 6 \epsilon_{0}$, and $9 \epsilon_{0}$. The other potential interactions were taken as $\epsilon=\epsilon_{0}$. In annealing, the temperature was decreased form $1100 \mathrm{~K}$ to $400 \mathrm{~K}$ during $8 \mathrm{~ns}$.

Figure 5 shows the typical configurations of the developer chains obtained after $4 \mathrm{~ns}$ at a constant temperature, $400 \mathrm{~K}$. For the head potential parameter $\epsilon=3 \epsilon_{0}$, the developer chains make some ordered (layer) domains. These domains disperse in 


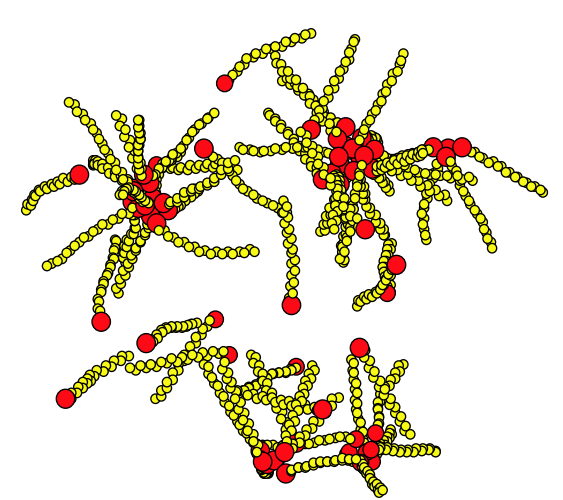

(a)box size $80 \AA$

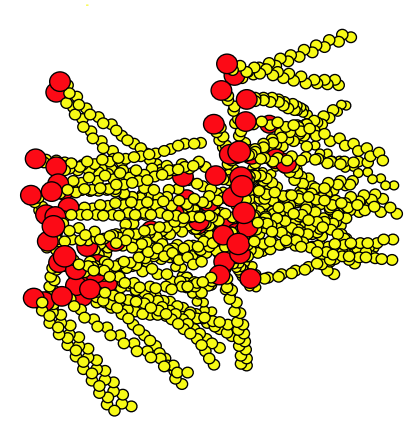

(b)box size $40 \AA$

Figure 4. The change of simulation box size from (a) $80 \AA$ to (b) $40 \AA$ at $282 \mathrm{~K}$ $(\beta=1.6)$.

parts, because the attractive energy of the head monomer is not large enough. For the potential parameter $9 \epsilon_{0}$, the developer chains also exhibit some ordered (layer) domains. These domains aggregate each other closely but irregularly because the head potential energy is too large. For the head potential parameter $6 \epsilon_{0}$, the developer chains show a clear lamellar structure. From our analysis of the pair distribution function of the centers of gravity of each developer, the peak corresponding to the length of the developer chains is significantly higher for $\epsilon=6 \epsilon_{0}$ than that for other potential two cases.

In figure 6 the time development of $\left\langle\cos \theta^{2}\right\rangle$ is shown, in which $\theta$ is the angle between any pair of developers (chains) and $\left\langle\cos \theta^{2}\right\rangle$ is an average over all pairs. It turns out that for case (b) the number of pairs of developers belonging to $\cos ^{2} \theta=$ $0.9 \sim 1.0$, which is shown by the blue curve, is significant, compared with the other two cases. They exhibit a remarkable increase after $4 \times 10^{6}$ time steps. This is consistent with the configurations shown in figure 5 .

Figure 7 shows the partial pair distribution function of head monomers for various $\epsilon$ (in terms of $\epsilon_{0}$ ). The first peak, which corresponds to the nearest head head neighbour, is increased rather monotonously as the head to head interaction is increased. This is not surprising.

In figure 8 the time autocorrelation function of unit vectors along each developer is shown. It is seen that the time dependence changes rather drastically between $\epsilon / \epsilon_{0}=4.5$ and 6 . For $\epsilon / \epsilon_{0} \geqslant 6$ it exhibits a significant slow behaviour, compared to that for $\epsilon / \epsilon_{0} \leqslant 4.5$.

Figure 9 shows an illustration which summarizes the present result obtained by the molecular dynamic simulation in 2D. 
case(a)

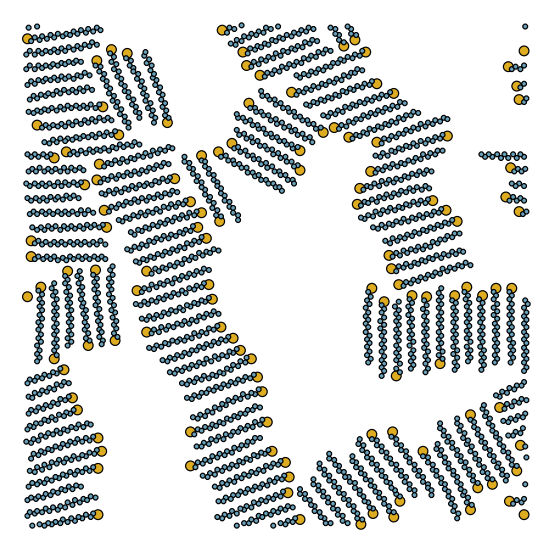

case(b)

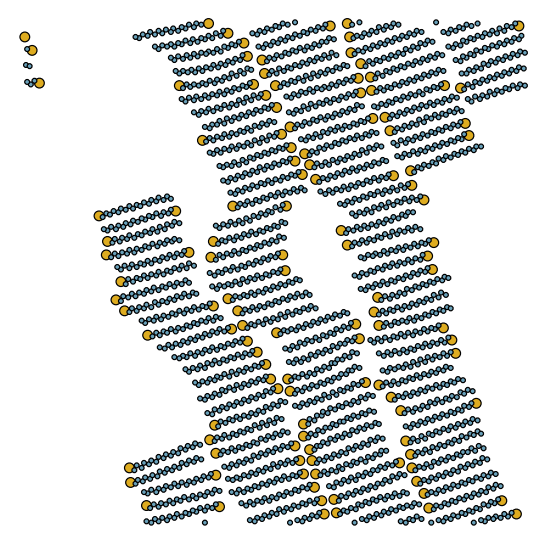

\section{case(c)}

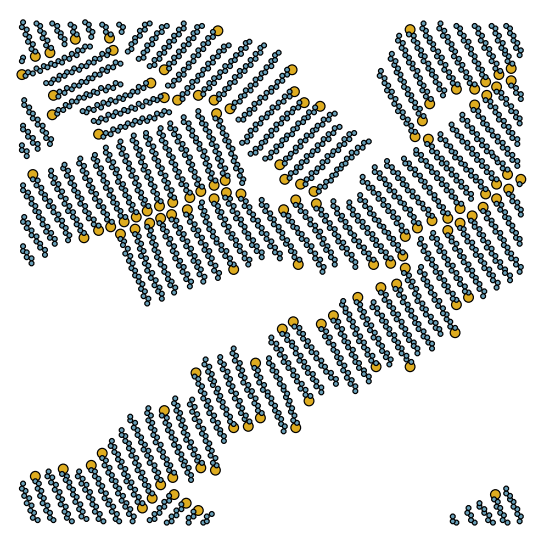

Figure 5. The typical configurations of the developers obtained by molecular dynamics simulations for three different cases (a) $\epsilon / \epsilon_{0}=3$, (b) $\epsilon / \epsilon_{0}=6$, and (c) $\epsilon / \epsilon_{0}=9$. 

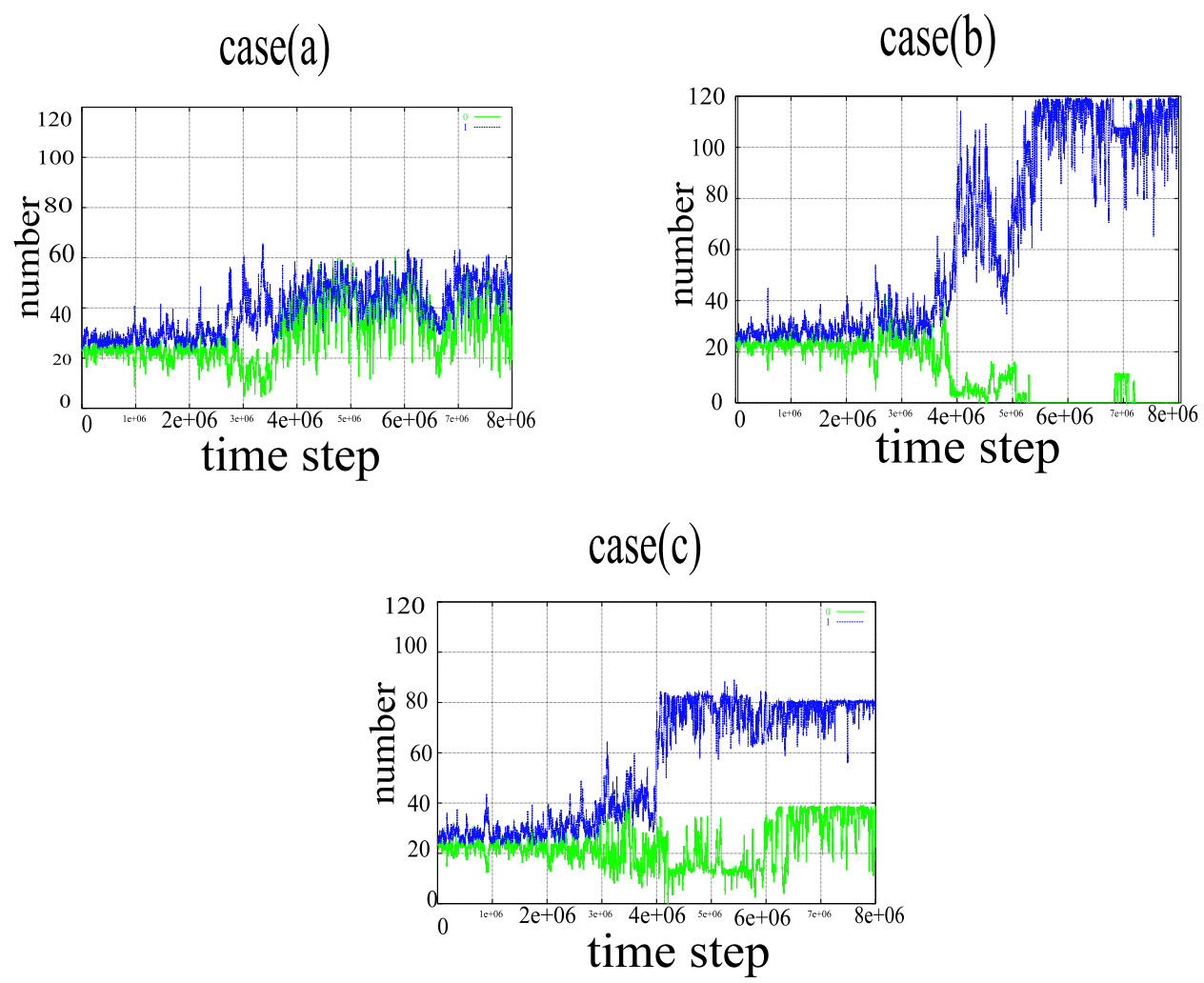

Figure 6. Time development of $\left\langle\cos \theta^{2}\right\rangle$, where $\theta$ is the angle between any pair of developers.

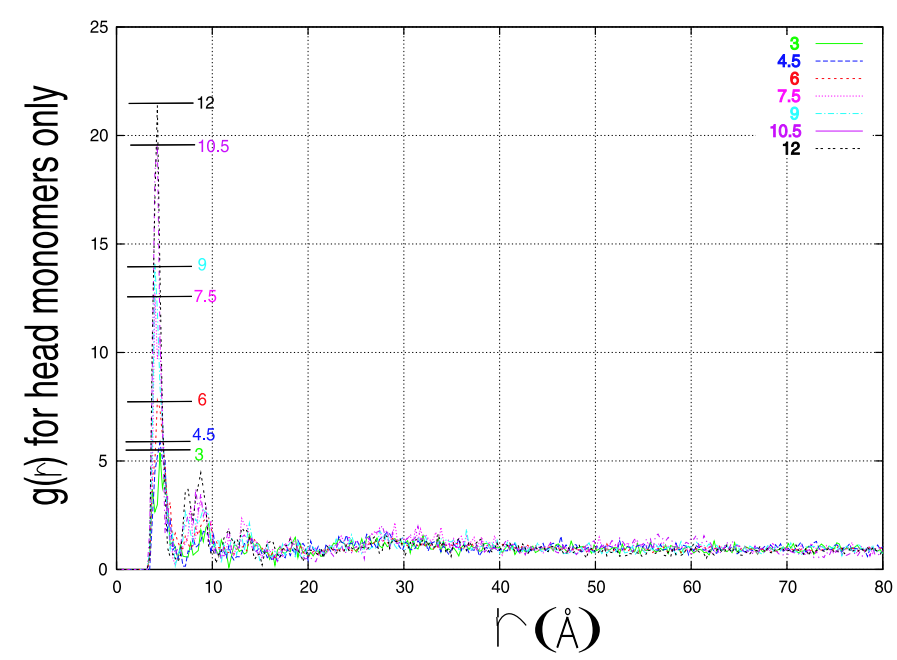

Figure 7. Partial pair distribution function $\mathrm{g}(\mathrm{r})$ for the head monomers alone. The numbers shown in the figure denote the values of $\epsilon / \epsilon_{0}$. 


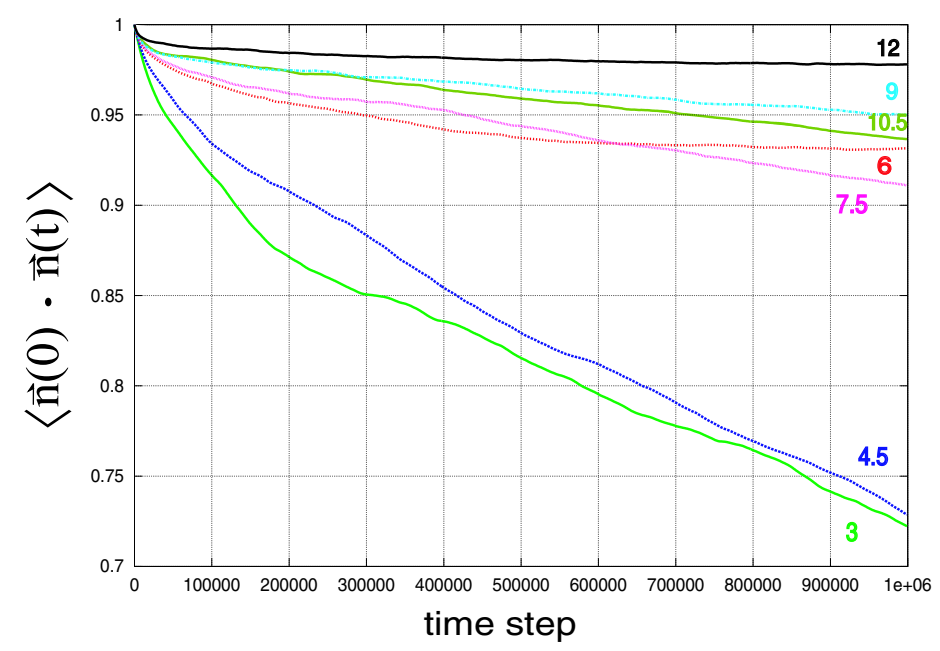

Figure 8. Time autocorrelation function $\langle\bar{n}(0) \cdot \bar{n}(t)\rangle$, where $\bar{n}$ is a unit vector along each developer. See also the captions of figure 7 .

\begin{tabular}{|c|c|c|c|}
\hline & TypeA & TypeB & TypeC \\
\hline & 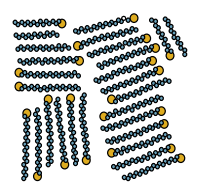 & 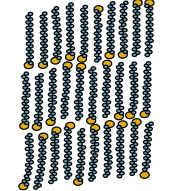 & 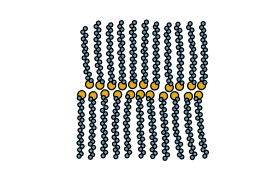 \\
\hline$\varepsilon / \varepsilon_{0}=$ & $3,4.5$ & 6 & $7.5,9,10.5,12$ \\
\hline & $\begin{array}{l}\text { disordered layer } \\
\text { structures }\end{array}$ & $\begin{array}{l}\text { ordered layer } \\
\text { structures } \\
\text { (lamellar) }\end{array}$ & $\begin{array}{l}\text { bi-layer } \\
\text { structures }\end{array}$ \\
\hline
\end{tabular}

Figure 9. Illustration of disordered layer structure, ordered layer structure and bi-layer structure, associated with the strength of the head to head interaction. 
It is suggested that the developer chains hardly form the lamellar structures, when the head potential energy is either too small or too large. Thus we conclude that the head potential energy of the developer chain plays an important role in forming the lamellar structures.

\section{Conclusion}

From Monte Carlo simulations for three dimensions, it turns out that the developer chains aggregate notably at the temperature $282 \mathrm{~K}$. The developer chains exhibit some aggregated domains. In these simulations, any clear lamellar structure was not obtained because the concentration of the developer chains was very low. It is naturally predicted that if the concentration of the developer chains is increased, the domains of the developer chains aggregate to each other and the developer chains form inevitably lamellar structures (bi-layer at least) at high concentrations. The transition from the dispersed state to the aggregated state corresponds to the colouring to decolouring process in real CR films. From the molecular dynamics simulations for two dimensions, we obtained a clear lamellar structure of the developer chains for the case that the interaction between the head monomers is $6 \epsilon_{0}$. The lamellar structure well corresponds to the colouring/decolouring structures of the developers. The head potential energy of the developer chains plays a key role for obtaining the lamellar structure. If the attractive interaction between the head monomers is either too small or too large, it is rather difficult to form the lamellar structure. The colouring to decolouring process may depend on the cooling rate. We will further investigate the effect of the cooling rate upon the formation of the structure of developers. These studies will be of a great importance for a new development of the colour rewritable films, which are currently undertaken.

\section{Acknowledgements}

This research is supported by "Research and Development Applying Computational Science and Technology" of Japan Science and Technology Corporation (JST).

\section{References}

1. Tsutsui K., Yamaguchi T., Sato K. Thermochromic properties of mixture systems of octadecylphosphonic acid and fluoran dye. // Jpn. J. Appl. Phys., 1995, vol. 33, p. 59255928.

2. Tsutsui K., Yamaguchi T., Sato K. Effects of alkyl-chain length of alkylphosphonic acids on fluoran dye. // J. Chem. Soc. Japan, 1995, vol. 1, p. 68-73.

3. Furuya H., Torii M., Tatewaki T., Matsui H., Shimada M., Kawamura F., Tsutsui K. Improvement of colouring/decolouring characteristics for thermal rewritable recording Media using leuco dye. // Ricoh Technical Report, 1999, No. 25, p. 6-14. 
4. Yoneya M., Berendsen H.J.C., Hirasawa K. A non-interactive matrix method for constraint molecular dynamics. // Mol. Sim., 1994, vol. 13, p. 395-405.

5. Yoneya M., Ouchi T. Molecular dynamics simulations on shared-memory multiple processor computers. // Mol. Sim., 1995, vol. 15, p. 273.

6. Allen M. P., Tidesley D.J. Some tricks of the trade. In Computer simulation of liquids. // Oxford University Press, 1987, p. 140-181.

\title{
Вивчення методами Монте Карло і молекулярної динаміки кольорових записуючих плівок
}

\author{
Г.Окаїма ${ }^{1}$, Т.Кавамура ${ }^{1}$, С.Конго ${ }^{1}$, Й.Гіватарі ${ }^{1}$, \\ Н.Уракамі ${ }^{2}$, Р.Гаяші ${ }^{3}$, К.Като ${ }^{4}$ \\ 1 Відділення комп'ютерних наук, університет м. Каназави, \\ м. Каназава 920-1192, Японія \\ 2 Відділення фізики, біології і інформатики, \\ Університет м. Ямагучі, м. Ямагучі, 753-8512, Японія \\ 3 Японський вищий інститут науки і технології, \\ Ішікава, Японія \\ 4 Компанія "Рікон", Шізуока, 410-0004, \\ Японія
}

Отримано 25 липня 2000 р., в остаточному вигляді - 6 вересня 2000 p.

Структура проявників відіграє важливу роль в процесі забарвлення/знебарвлення для кольорових записуючих плівок. Ми вивчаємо ланцюжковоподібну полімерну структуру проявника методом Монте Карло і молекулярної динаміки. В цих моделюваннях ми зосереджуємо увагу як на термічних (температурних) ефектах так і на ефективній взаємодії між проявниками (ланцюжково подібними полімерами) і на тому як шарувата структура може бути сконструйована, коли система є різко охолоджена від високої температури (низької густини) до низької температури (високої густини). Ми знайшли перехід станів з невпорядкованого стану до агрегатного стану при температурі (282 K). Ми отримали шарувату структуру при певній умові потенціального параметра, тоді як при слабких і сильних взаємодіях шарувата структура проявника формується важко.

Ключові слова: кольорова записуюча плівка, проявник, шарувата структура, метод Монте Карло, метод молекулярної динаміки

PACS: 05.70.Jk 
